\title{
The Effect of Human and Rat Fetal Bone on Hematopoiesis In Vitro and In Vivo
}

\author{
B.V. Afanasyev, V.A. Shatrov, and N. Balayan
}

Granulocyte-macrophage colony-stimulating factor (GM-CSF) is a regulatory glycoprotein necessary for the proliferation, maturation, and survival of myeloid cells [4]. Myelopoiesis is enhanced when recombinant human (rh) GM-CSF is given to mice, monkeys [6], and some patients with various forms of neutropenia $[3,5]$. The clinical use of rhGM-CSF infusions is under intensive investigation now.

An alternative way of increasing the level of GM-CSF in the organism is by transplantation of CSF-producing cells, analogous to the transplantation of insulin-producing cells in patients with diabetes mellitus. It seems especially important to increase the intramedullary concentration of GM-CSF, as bone marrow is the central organ for regulating the proliferation and differentiation of hematopoietic cells. There is a positive correlation between the intramedullary concentration of GM-CSF and the prognosis for patients with leukemia [8]. One source of CSF-producing cells may be various embryonal cells which are available and genetically more tolerable.

The main objectives of this study were: (a) to evaluate the ability of various human fetal organs and tissues to develop colony-stimulating and -inhibiting activities (CSA and CIA); (b) to estimate their effect on colony-forming unit-granulocyte macrophage (FU-GM) and leukemic clonogenic cells (LCC); (c) to evaluate the effect of fetal bone (FB) on fibrous tissue of adult bone marrow in

N.N. Petrov Institute of Oncology, Department of Bone Marrow Transplantation, Leningrad, USSR vitro; and (d) to evaluate the effect of rat FB transplantation into rats after lethal and sublethal doses of cyclophosphamide.

\section{A. Material and Methods}

A total of 88 human fetuses (24 at 7-10 weeks; 38 at $11-15$ weeks; 22 at $20-26$ weeks) were used to evaluate CSA and CIA of various fetal organs and condition media $(\mathrm{CM})$. Bone marrow cells of 87 hematologically healthy donors (control group), 92 patients with various hematological disorders, and 48 human fetuses (7 at $10-12$ weeks; 10 at $13-15$ weeks; 16 at $20-22$ weeks; 15 at $23-26$ weeks) were used as target cells. The cloning of hematopoietic cells was performed in agar drop-liquid medium [1]. CSA of fetal tissues (FT) or CM (CMFT) was estimated as: the number of aggregates in the plates with FB or CMFT divided by the number of aggregates in the plates with leukocyte feeder (F). IA was calculated as: CSA of F (100\%) - CSA of (F + FT or CMFT).

Colonies and clusters were scored at day 7 or 8 . The effect of FB on fibrous tissue was studied by morphometric assay of bone marrow trephine biopsy after its cultivation using the Marbrook system [2] with or without FB. The scheme of rat FB transplantation is presented in Fig. 1.

\section{B. Results and Discussion}

All human fetal tissues except from the liver were able to produce CSA in vitro 


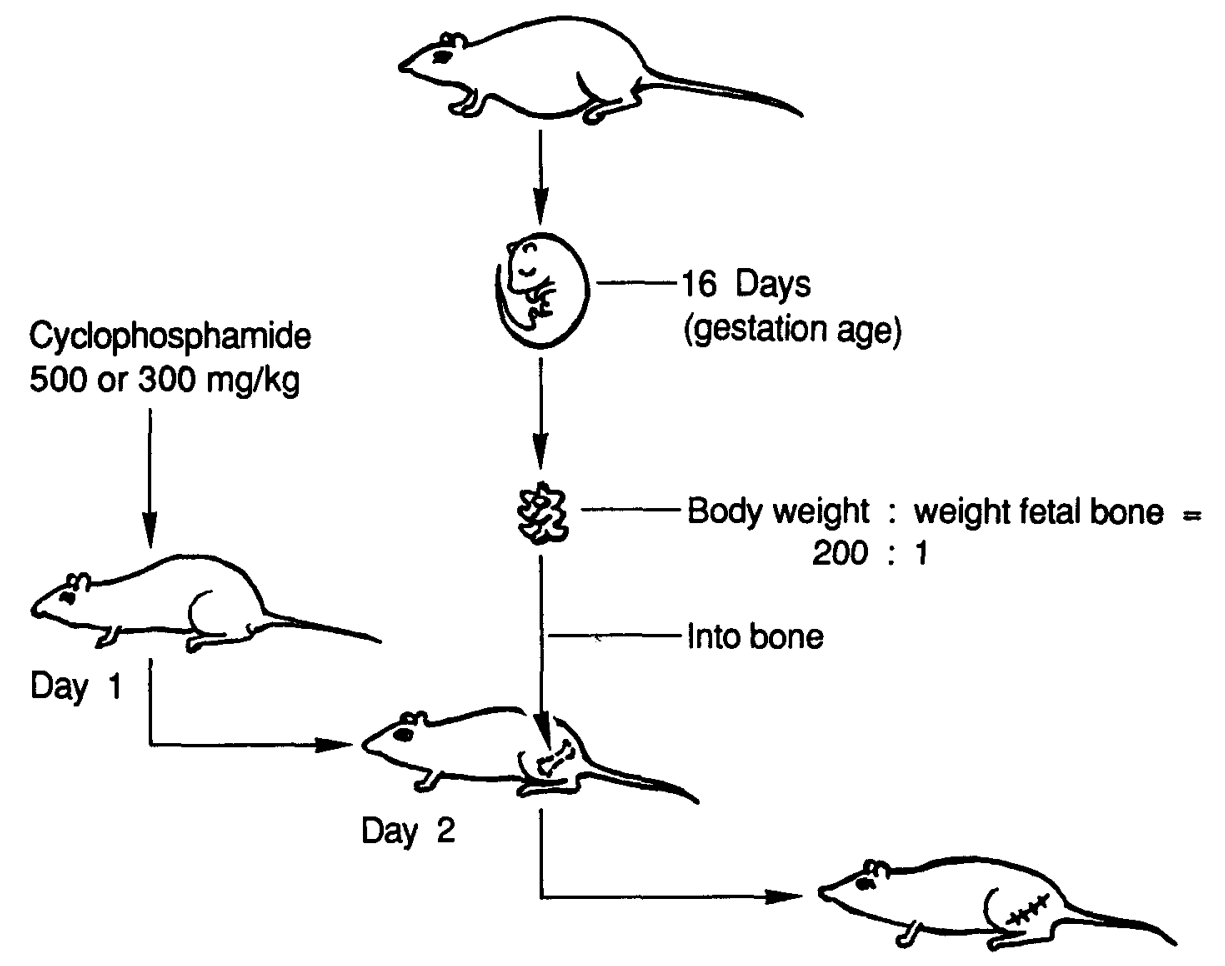

Days $3-86$
Fig. 1. Scheme of fetal bone transplantation in rat

Table 1. Colony-stimulating activity (CSA) and colony-inhibiting activity of human fetal bone (mean $\pm S D$ )

\begin{tabular}{lcll}
\hline Target cells & $\begin{array}{l}\text { Range of spontaneous } \\
\text { colony formation }\end{array}$ & $\begin{array}{l}\text { CSA of fetal bone } \\
\text { (\% leukocyte feeder) }\end{array}$ & $\begin{array}{l}\text { CIA of fetal bone } \\
\text { (Leukocyte feeder } \\
\text { +fetal bone) }\end{array}$ \\
\hline Control group & 0 & $62.8 \pm 8.2$ & $100-80.6 \pm 15.7$ \\
& $61.8 \pm 27.4$ & $85.0 \pm 10.4$ & $100-80.4 \pm 11.3$ \\
Acute nonlymphocytic & 0 & $42.9 \pm 11.1$ & $100-110.9 \pm 19.1$ \\
leukemia & $52.7 \pm 15.5$ & $67.8 \pm 9.2$ & $100-115.1 \pm 14.3$ \\
Fetal bone marrow & 0 & $50.2 \pm 7.2$ & $100-52.0 \pm 7.7$ \\
& $46.7 \pm 15.5$ & $99.0 \pm 11.4$ & $100-74.0 \pm 7.9$ \\
\hline
\end{tabular}

Numerator, low level of spontaneous colony formation; denominator, high level of spontaneous colony formation

(Fig. 2), but FB was the only tissue which sustained this capacity for at least 4 weeks. The cocultivation of FB and AML (acute myeloid leukemia) or normal bone marrow in liquid culture for 2 weeks did not decrease the capacity of FB to produce CSA. The LCC were more sensitive to the endogenous stimulators and demonstrated less response to FB stimulation than normal CFU-GM (Table 1). With prolonged cultivation time of the AML bone marrow, morphometric analysis of trephine biopsy using the Marbrook system showed an increased proliferation of fibrous tissue and a disappearance of hematopoietic elements (Table 2). On the other hand, the cocultivation of trephine biopsy and FB inhibited the proliferation of fibrous tissue and prevented the destruction of hematopoietic cells. The cultivation of FB for 4 weeks in liquid medium or 
Fig. 2. Colony-stimulating activity $(C S A)$ in various fetal tissues. •, Kidney; $\Delta$, spleen; $\mathbf{E}$, lung; $\circ$, liver; $\Delta$, muscle; $\square$, thymus; $\triangleleft$, bone
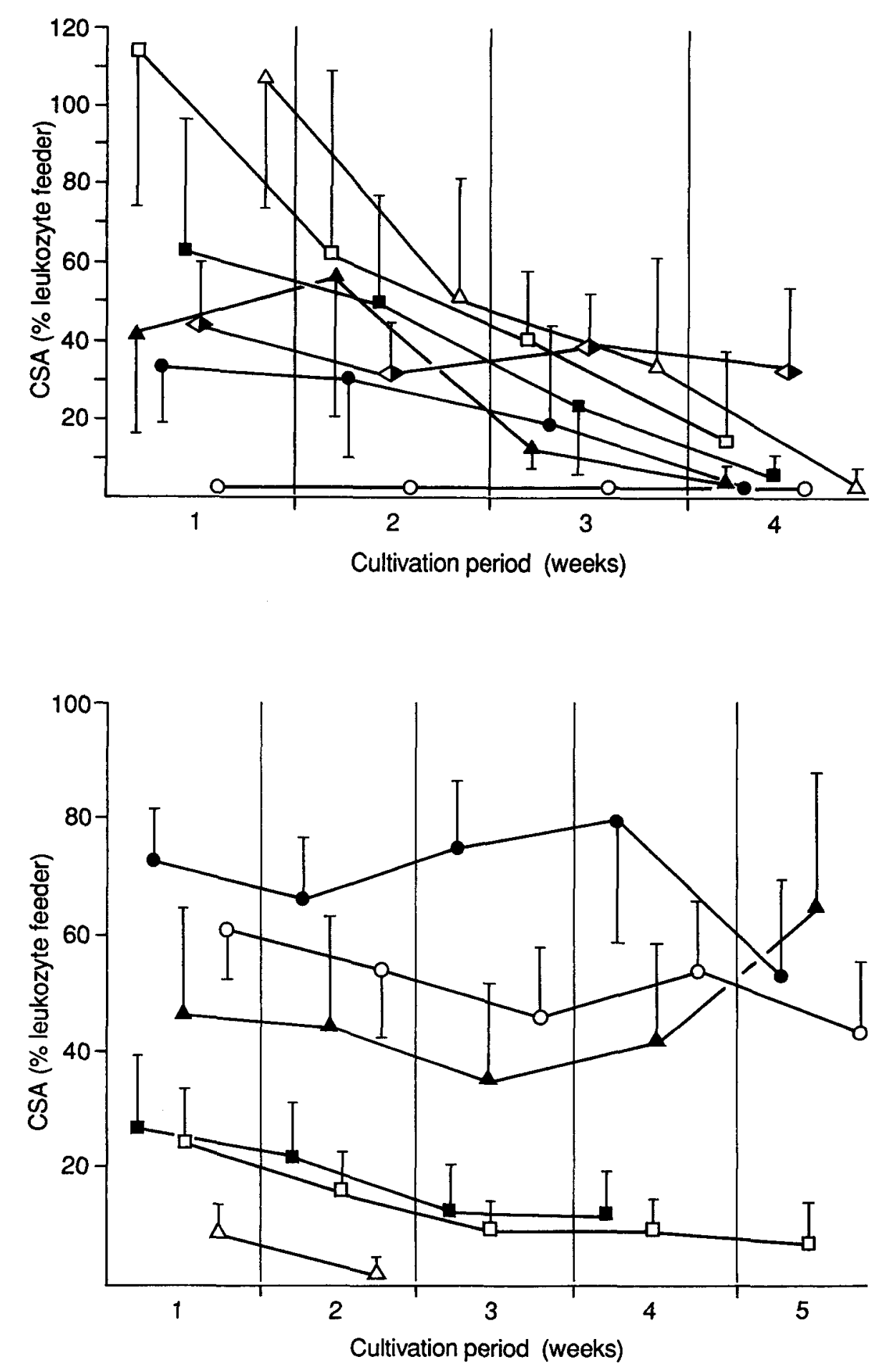

Fig. 3. Colony-stimulating activity (CSA) of human fetal bone (FB) under different perservation conditions.

-, Control; $\triangle$, FB after cryopreservation; $\square$, crushed FB after cryopreservation; $\mathrm{O}, \mathrm{FB}$ preserved at $+4^{\circ} \mathrm{C}$ for 1 week; $\square$, FB preserved at $+4^{\circ} \mathrm{C}$ for 2 weeks; $\Delta$, FB preserved at $+4^{\circ} \mathrm{C}$ for 4 weeks cryopreservation at $-196^{\circ} \mathrm{C}$ with $10 \%$ DMSO did not considerably affect its capacity for CSA production (Fig. 3). The transplantation of FB shortened the period of leukocytopenia after sublethal $(300 \mathrm{mg} / \mathrm{kg})$ or lethal $(500 \mathrm{mg} / \mathrm{kg})$ doses of cyclophosphamide in a rat model (Fig. 4) and increased the probability of survival (Fig. 5).

Thus, rat survival after FB transplantation was increased. This effect is proba- bly related to the ability of $\mathrm{FB}$ to give long-term CSF production and the increase of the intramedullary CSF level. We have shown that FB induced the proliferation of LCC. FB has been suggested to exert a differentiated effect on LCC, which can return to their normal phenotype [7]. Moreover, FB inhibits fibrous tissue proliferation in human AML bone marrow. Further research is needed to establish the place of FB transplantation in clinical practice. 
Table 2. Results of cultivation of bone marrow tissue in Marbrook system in the presence of human fetal bone (morphometric assay bone marrow trephine biopsies from the acute nonlymphocytic leukemia patients)

\begin{tabular}{lcrll}
\hline $\begin{array}{l}\text { Cultivation period } \\
\text { (weeks) }\end{array}$ & \multicolumn{2}{l}{ Type of tissue (\%) } & \\
\cline { 2 - 5 } & Hemopoietic (\%) & Fat (\%) & Bone (\%) & Fibrous (\%) \\
\hline 1 & $7-45$ & $4-80$ & $12-28$ & $0-10$ \\
& $17-38$ & $26-54$ & $12-19$ & 0 \\
2 & $0-20$ & $11-70$ & $15-40$ & $8-42$ \\
3 & 80 & $24-32$ & $13-16$ & 0 \\
& 0 & $0-25$ & $20-54$ & $25-50$ \\
$4-5$ & $8-28$ & $18-24$ & $23-28$ & $0-3$ \\
& 0 & $4-9$ & $16-32$ & $30-60$ \\
& $21-30$ & $45-57$ & $12-20$ & $0-3$ \\
\hline
\end{tabular}

Numerator, bone marrow trephine (BMT); denominator, BMT + fetal bone

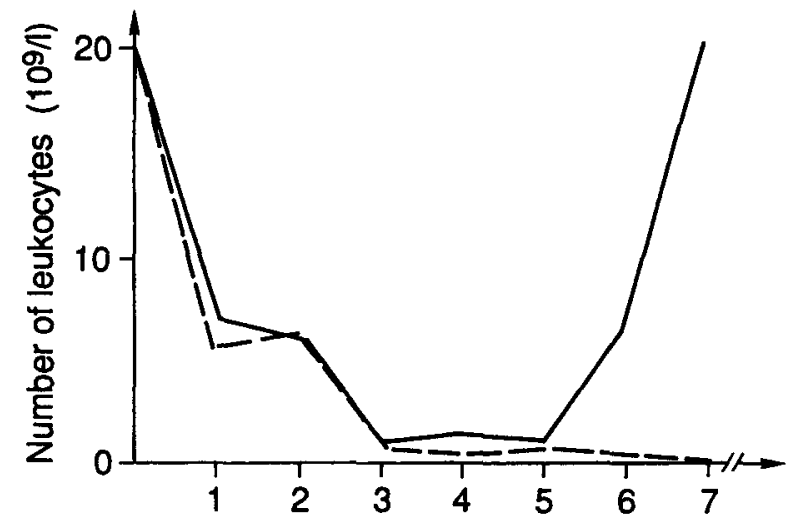

$\mathbf{a}$

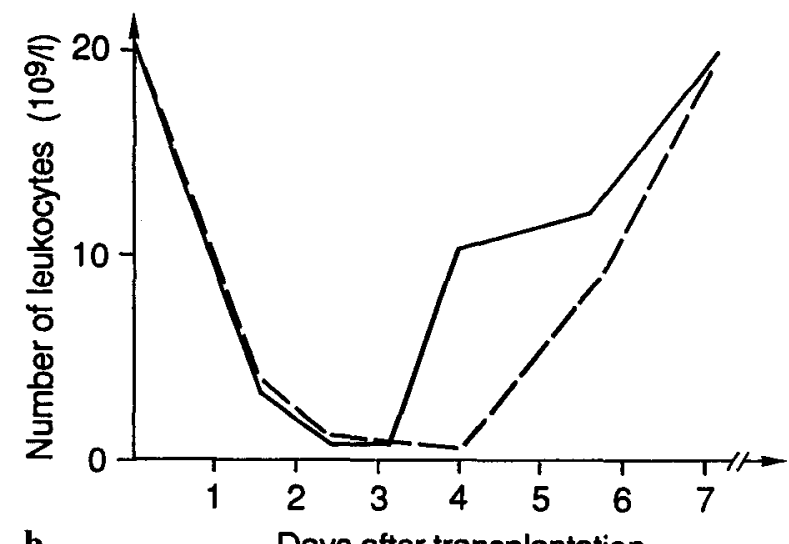

Days after transplantation

Fig. 4 a, b. Leukocyte count in peripheral blood after fetal bone transplantation. a Administration of $500 \mathrm{mg} / \mathrm{kg}$ cyclophosphamide. b Administration of $300 \mathrm{mg} / \mathrm{kg}$ cyclophosphamide. Solid curve, experimental group; broken curve, control group
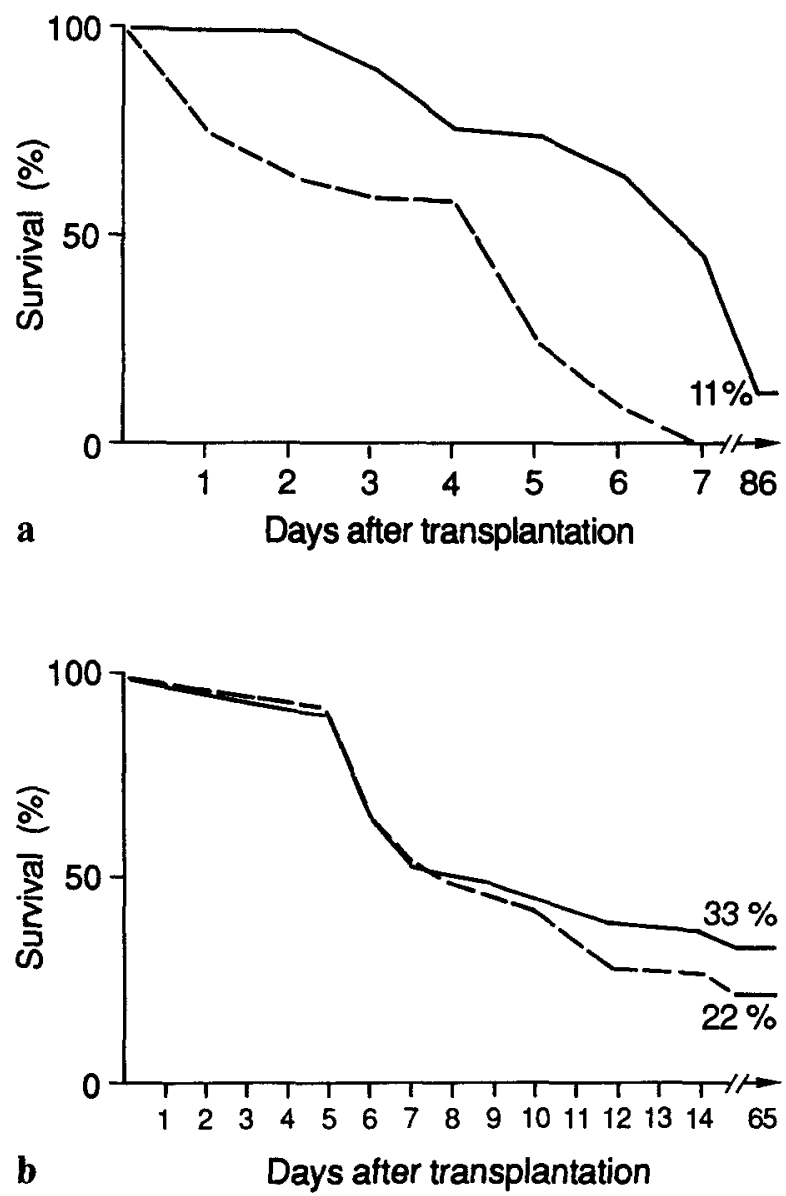

Fig. 5a, b. Survival rate after fetal bone transplantation. a Administration of $500 \mathrm{mg} / \mathrm{kg}$ cyclophosphamide $(p=0.001)$. b Administration of $300 \mathrm{mg} / \mathrm{kg}$ cyclophosphamide $(p=0.05)$. Solid curve, experimental group $(n=63)$; broken curve, control group $(n=42)$ 


\section{References}

1. Afanasyev BV, Tiranova SA, Kulibaba TG, Zubarovskaya LS, Bolshakova GD, Zabelina TS (1983) Cloning of human hemopoietic cells in the "agar drop-liquid medium" system. Ther Arch (USSR) 8:114

2. Golde DW, Cline MJ (1973) Growth of human bone marrow in liquid culture. Blood 41:45

3. Groopman JE, Mitsuyasu RT, DeLeo MJ, Oette DH, Golde DW (1987) Effect of recombinant human granulocyte macrophage colony stimulating factor on myelopoiesis in the acquired immunodeficiency syndrom. N Engl J Med 317:593

4. Metcalf D (1977) Haemopoietic colonies. Springer,Berlin Heidelberg New York

5. Nemunaitis J, Singer JW, Buckner CD, Hill R, Storb R, Thomas ED, Appelbaum FR (1988) Use of recombinant human granulocyte macrophage colony stimulating factor (rh GM-CSF) in autologous marrow transplantation for lymphoid malignancies. Blood 72: 834

6. Nienhuis AW, Donahue RE, Karisson S, Clark SC, Agricola B, Antihoff N, Pierce JE, Turner P, Anderson WF, Nathan DG (1987) Recombinant human granulocyte macrophage colony stimulating factor (GM-CSF) shortens the period of neutropenia after autologous bone marrow transplantation in a primate model. $\mathrm{J}$ Clin Invest 80:573

7. Pierce GB (1983) The cancer cell and its control by the embryo. Am J Pathol 113: 117

8. Zubarovskaya LS, Afanasyev BV, Smirnova GA, Lukasheva TN, Patterson D, Shishkov AL, Balayan LN, Ostrovsky AM (1985) Colony-stimulating activity of bone marrow trephanobiopsies of patients with different pathological conditions of the blood system. Ther Arch (USSR) 7:22 